\title{
PRODUCTIVITY, LIPID CONTENT AND FATTY ACID COMPOSITION OF SOME SELECTED CYANOBACTERIAL STRAINS UNDER DIFFERENT GROWTH CONDITIONS
}

\author{
Fekry M. Ghazal ${ }^{a}$, Ola I. Hammoudab ${ }^{b}$ Mohamed S. AbdeL Hameed , $^{\text {, }}$ \\ Sherif H. Hassan ${ }^{\mathrm{b}, *}$ and Seham M. Hamed ${ }^{\mathrm{a}}$
}

a. Soils, Water and Environ. Inst., Agric. Res. Center, Giza, Egypt

b. Botany Department, Faculty of Science, Beni-Suef University, Beni-Suef, Egypt

\begin{abstract}
The present study is a trial to cultivate three different cyanobacterial strains (Anabaena laxa, Anabaena fertilissima and Nostoc muscorum) under four different growth conditions using $\mathrm{BG}_{1} 1_{0}$ growth medium. These conditions are represented by static glucose medium with glucose $(1 \%, \mathrm{w} / \mathrm{v})$, aerated medium (aerated by bubbling technique depending on atmospheric $\mathrm{CO}_{2}$ normally existed in air with a concentration of $0.3 \%$ ), growth medium enriched with molasses of sugar cane $(0.7 \%, \mathrm{v} / \mathrm{v})$ and aerated growth medium enriched with glucose $(1 \%$, w/v). A. laxa, A. fertilissima and $N$. muscorum exhibited high biomass production under mixotrophic growth condition rather than aerated autotrophic condition. Whereas, static glucose medium enhanced the growth of A. laxa, A. fertilissima and N. muscorum significantly with dry weight yield of $3.6,3.1$ and $5.2 \mathrm{~g} \mathrm{~L}^{-1}$, respectively. Moreover, glucose enhanced lipid content for both A. laxa and N. muscorum to produce 293.9 and $253.5 \mu \mathrm{g} \mathrm{g}^{-1}$ fresh wt., respectively. While A. fertilissima exhibited the highest lipid content under aerated enriched glucose medium ( $307.6 \mu \mathrm{g} \mathrm{g}^{-1}$ fresh wt.). Static glucose medium supported the lipid synthesis rate of $N$. muscorum to record 6.3 folds, as compared to the control, after 10 days of treatment. While A. fertilissima exhibited its highest lipid synthesis rate under aerated enriched glucose condition after 2 days. Ten fatty acids were detected for all the investigated cyanobacterial strains with different percentages, under static glucose medium $(1 \%, \mathrm{w} / \mathrm{v})$ during the stationary phase. Half of them were saturated fatty acids and the others were two mono-unsaturated and three poly-unsaturated fatty acids. Myristic, palmitoleic and arachidonic acids were the most abundant among all the tested isolates.
\end{abstract}

Key words: Cyanobacteria; mixotrophy; autotrophy; lipid content; fatty acids

\section{Introduction}

Commercial use of microalgae as sources of specific lipids began in the 1970s with the extraction of b-carotene from Daunanella salina (Raja et al., 2008). 
Interest in docosahexaenoic (DHA) has increased recently because of the recognition that $\omega 3$ - polyunsaturated fatty acids are important for good health and in lowering the risk of diseases where chronic inflammation plays an important role (Harwood and Caterson, 2006). This includes cardiovascular disease, various cancers, arthritis and dementia. Among many types of algae, microalgae seem to be promising because they have high growth rates (Rittmann, 2008). Their lipid content could be adjusted through changing growth medium composition (Naik et al., 2006). Quantitatively, the total lipid content varies between species ranging from very low (4.5\%) to very high (80\%) (Renaud $\boldsymbol{e t}$ al., 1999; Hu et al., 2008). Several microalgae such as Chlorella protothecoides (Wu et al., 1992), Crypthecodium cohnii (de Swaaf et al., 2003 a\&b) are capable of uptaking carbohydrates (e.g., glucose) directly and transforming them to lipid (Miao et al., 2006). Nostoc spp. can grow mixotrophically, using glucose and sugarcane molasses as organic substrates, and greater production of biomass and phycobiliproteins can be reached when compared with the autotrophic growth (Borsari et al., 2007). Also, Anabaena sp. PCC 7120 was grown in the presence of exogenous glucose in light (Guoce et al., 2011). Microalgae can be cultured in heterotrophic conditions where organic carbons, such as sugars, sugarcane molasses and organic acids, serve as carbon sources. Accordingly, the lipid content for a particular species depends on growth phase with lowest yields common for logarithmic-increasing in late logarithmic- and stable or increasing in stationary phase (Hu et al., 2008; Xu et al., 2008). Microalgal lipids can be changed with variations in nutrients, temperature, salinity, $\mathrm{pH}$, photoperiod, light intensity and light quality (Dunstan et al., 1993). During the optimal conditions for growth, microalgae synthesize glycerol-based membrane lipids that are mainly composed of various polyunsaturated fatty acids (Hu et al., 2008). During stress conditions, such as limitation in nutrients, microalgae shift their lipid biosynthetic pathways and start accumulating large quantities of neutral lipids (Dunstan et al., 1993). The neutral lipids are mostly triglycerides that serve primarily as a storage form of carbon and energy (Hu et al., 2008) and they can account for as much as $80 \%$ of the total lipid content in the cell (Meng et al., 2009). Generally, microalgal triglycerides contain saturated and monosaturated fatty acids with $\mathrm{C}_{16}$ and $\mathrm{C}_{\mathrm{I} 8}$ profile (Bertoldi et al., 2006; Hu et al., 2008; Meng et al., 2009). Microalgae with higher levels of triacylglycerol should contain higher proportion of saturated and monosaturated fatty acids and lower proportion of polyunsaturated fatty acid (Dunstan et al., 1993). In addition, it was reported that microalgae contain more variations in fatty acid composition than higher plants (Bertoldi et al., 2006; Hu et al., 2008). This study aimed to investigate the capability of Anabaena laxa (Rabenhorst) Braun A, Anabaena fertilissima and Nostoc muscorum to grow in mixotrophic culture to assay the testing glucose and sugarcane molasses as substrates. Also, to assess the potential of both Anabaena $s p$ and Nostoc sp. to be used to transform carbon from flue gases or from organic sources into valuable products. 


\section{Material and Methods}

\section{Isolates and growth medium}

Anabaena laxa (Rabenhorst) Braun A, Anabaena fertilissima Rao CB and Nostoc muscorum Agardh C were obtained from the culture collection of soils, water and environment research institute at agriculture research center, Giza, Egypt. B.G11 $1_{0}$ (nitrogen free) medium was prepared according to Allen's and Stanier (1968). The isolates were grown in 250 -ml Erlenmeyer flasks at $28 \pm 2^{\circ} \mathrm{C}$ with continuous illumination at intensities of 2500 Lux

\section{Experimental Set up}

\section{Growth conditions}

The investigated cyanobacterial isolates were sub-cultured, separately, in 5 L Erlenmeyer bottles, containing 3 L B.G11 ${ }_{0}$ (nitrogen free) medium inoculated with $30 \mathrm{ml}$ of pre-cultured isolates during exponential phase. These isolates were cultured under four growth conditions (treatments). a) Autotrophic growth condition, each isolate was aerated by bubbling air at regular pressure $(200 \mathrm{ml}$ $\min ^{-1}$ with $50 \mathrm{~Hz}$ frequency), and closed by rubber plug having a narrow glass tube as an air outlet. This condition was depending on $\mathrm{CO}_{2}(0.3 \%)$ which exist normally in air, $\mathrm{b}$ and c) Mixotrophic growth conditions, were created by adding glucose $(1 \%, \mathrm{w} / \mathrm{v})$ and molasses of sugar cane $(0.7 \%, \mathrm{v} / \mathrm{v})$ separately, respectively, to the growth media under static condition (without aeration), and d) the last one Mixotrophic growth condition was created by adding glucose (1\%, $\mathrm{w} / \mathrm{v}$ ) to the growth medium under aerated condition. Before bubbling into the cultures, the air was allowed to pass through a series of "wolf" bottles containing disinfecting solution of copper sulfate, mercuric chloride and sterilized water at the same time. All bottles were kept under the same conditions of temperature and light intensity.

\section{Growth parameters}

\section{Dry weight}

A definite volume of algal suspension $(50 \mathrm{ml})$ was centrifuged at $4000 \mathrm{rpm}$ for $10 \mathrm{~min}$. The cell pellets were washed twice with distilled sterilized water and dried over night in an oven at $80^{\circ} \mathrm{C}$ for constant weight $\left(\mathrm{g} \mathrm{1}^{-1}\right)$ (Leganse $\boldsymbol{e t}$ al., 1987).

\section{Chlorophyll (a) content}

The spectrophotometeric method recommended by Arnon (1949) was used for the estimation of chlorophyll $a$ pigment. A definite volume of well shaked algal suspension sample was homogenized in $80 \%$ acetone and kept in a freezer for about $24 \mathrm{~h}$, to ensure complete extraction. The extract was measured against 
blank of $80 \%$ acetone at 645 and $663 \mathrm{~nm}$. Chlorophyll $a$ fraction $\left(\mathrm{mgg}^{-1}\right.$ fresh weight) was determined by using the following equation: Chlorophyll $a$ content $=12.7 \mathrm{E}^{663}-2.69 \mathrm{E}^{645}$

\section{Total lipids determination}

Lipids were extracted from the algal isolates with chloroform/methanol $(1: 1$, $\mathrm{v} / \mathrm{v})$ by the method of Barnes and Blackstock (1973). The extracted lipids were determined by the phosphovaniline method. Briefly, $0.5 \mathrm{ml}$ of concentrated sulfuric acid was added to the extracted lipids and heated for $5 \mathrm{~min}$. in a boiling water bath and left to cool at room temperature. The phosphovaniline reagent ( $2.5 \mathrm{ml})$ was added to the unknown and the blank tubes $(0.5 \mathrm{ml}$ sulfuric acid) with vigorous shaking, and then left at room temperature for $10 \mathrm{~min}$. The developed color was measured at $520 \mathrm{~nm}$ by using spectrophotometer. The total lipids were determined against the standard calibration cholesterol curve.

Lipid content percentage (\%)

The percentage of isolate's lipid production at different growth media conditions were calculated from the following equation:

Lipid content $\%=100 \times\left(t_{n}-t_{0}\right) / t_{0}$. Where, $t_{n}$ and $t_{0}$ represented lipid content at times $t_{n}$, and $t_{0}$ within the experiment period.

\section{Fatty acids analysis}

An extra amount of the extracted lipid was taken for fatty acids analysis. The fatty acid composition was determined by gas chromatography system according to the method of Ronald and Ronald (1991). The carrier gas was Helium with flow rate of $1.9 \mathrm{ml} / \mathrm{min}$ and injector temperature was $250^{\circ} \mathrm{C}$. The column used was ZB-wax $30 \mathrm{~m} \times 0.25 \mathrm{~mm} \times 0.25 \mu \mathrm{m}$ with an oven initial temperature of $50^{\circ} \mathrm{C}$. Initial time was $2 \mathrm{~min}$ with rate of $10^{\circ} \mathrm{C} \mathrm{min}^{-1}$ and the final temperature was $250^{\circ} \mathrm{C}$ with FID detector, $300^{\circ} \mathrm{C}$.

\section{Statistical analysis}

Differences between treatments were assessed by one-way analysis of variance (ANOVA) by using Statistical Package for the Social Sciences (SPSS) software for Windows, version 11; SPSS Inc, Chicago, using the least significance difference test (LSD) at probability ( $p$ ) values $\leq 0.05$. The values were expressed as mean \pm standard deviation ( $\mathrm{SD}, \mathrm{n}=3$ ).

\section{Results}

Significant biomass production and increased dry weight of the investigated algal isolates was observed by adding glucose to the growth medium (Fig. 1). The highest dry weight was obtained at $12^{\text {th }}$ day for $N$. muscorum $\left(5.2 \mathrm{~g} \mathrm{l}^{-1}\right)$ followed by $3.6 \mathrm{~g} \mathrm{l}^{-1}$ and 3.1 for A. laxa and A. fertilissima at $10^{\text {th }}$ and $12^{\text {th }}$ day respectively. Aerated enriched glucose medium also enhanced biomass production for both $A$. 
laxa and A. fertilissima where they exhibited $3.4 \mathrm{~g} \mathrm{l}^{-1}$ at $6^{\text {th }}$ and $2.9 \mathrm{~g} \mathrm{l}^{-1}$ at $8^{\text {th }}$ compared to $1.6 \mathrm{~g} \mathrm{l}^{-1}$ at $12^{\text {th }}$ and $2.1 \mathrm{~g} \mathrm{l}^{-1}$ at $18^{\text {th }}$ under aerated medium and $1.1 \mathrm{~g} \mathrm{l}^{-1}$ at $4^{\text {th }}$ and 1.7 at $8^{\text {th }}$ under molasses $(0.7 \%, v / v)$ medium. $N$. muscorum exhibited no growth on molasses $(0.7 \%, \mathrm{v} / \mathrm{v})$ medium. But it showed high dry weight on aerated medium $\left(1.4 \mathrm{~g} \mathrm{l}^{-1}\right.$ at $8^{\text {th }}$ day) compared to aerated enriched glucose medium (1.2 $\mathrm{g}^{-1}$ at $6^{\text {th }}$ day). It seems from this data that addition of organic carbon sources is not favorable for biomass production for this organism.
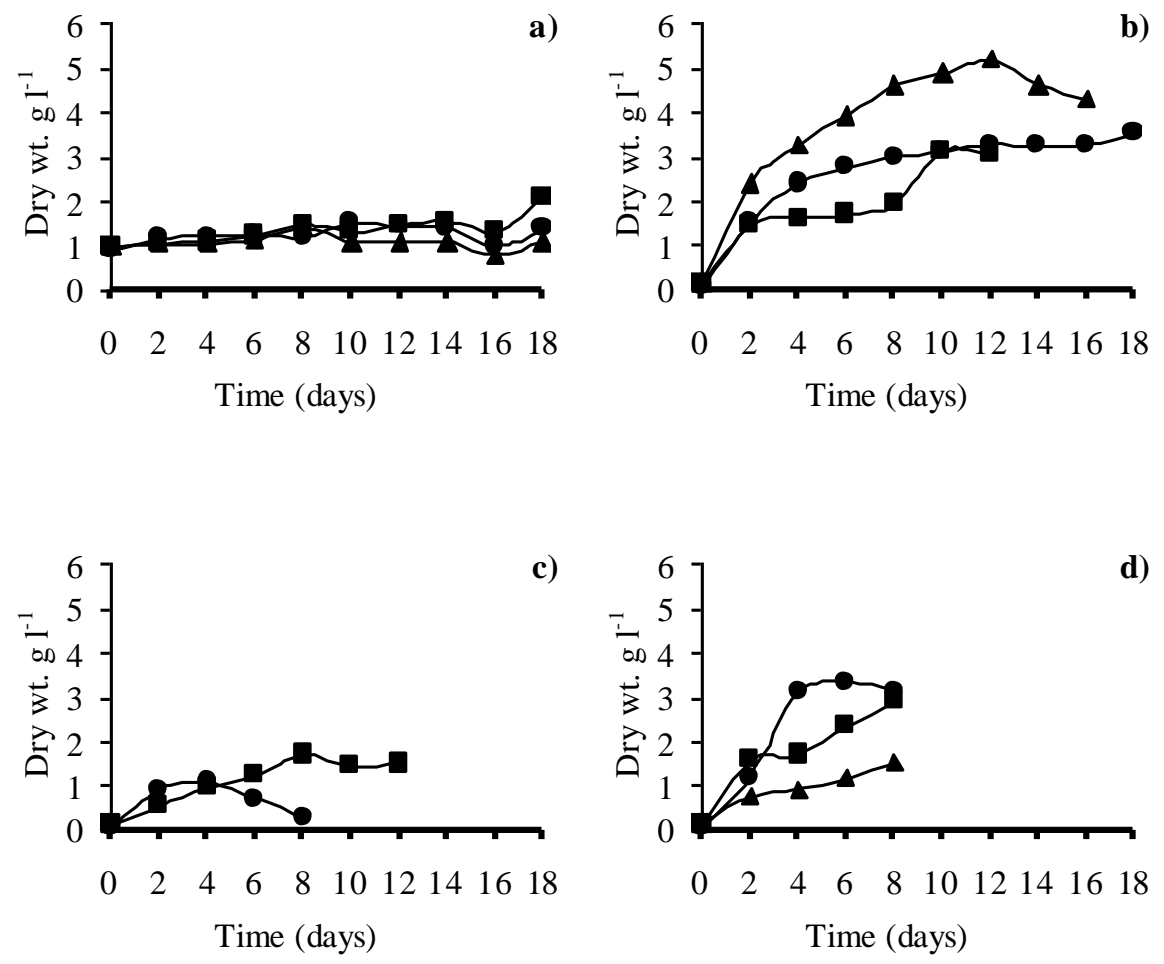

Figure 1. Dry weight content $\left(\mathrm{g} \mathrm{L}^{-1}\right)$ of Anabaena laxa $(O)$, Anabaena fertilissima ( $(\square)$ and Nostoc muscorum $(\triangle)$ at different growth media conditions a) aerated $(0.3 \%$ $\left.\mathrm{CO}_{2}\right)$, b) static glucose $\left.(1 \%, \mathrm{w} / \mathrm{v}), \mathrm{c}\right)$ molasses $(0.7 \%, \mathrm{v} / \mathrm{v})$ and d) aerated enriched glucose $(1 \%, \mathrm{w} / \mathrm{v})$ medium. Values are the mean of three replicates.

The highest chlorophyll $a$ values were obtained under aerated conditions i.e. absence of organic carbon sources and under continuous light illumination (Fig. 2). Where A. laxa exhibited the highest chlorophyll content $\left(99.3 \mathrm{mg} \mathrm{l}^{-1}\right.$ after 18 days) followed by $N$. muscorum $\left(42.4 \mathrm{mg} \mathrm{l}^{-1}\right.$ for after 14 days. Whereas, $A$. fertilissima exhibited its highest chlorophyll content under mixotrophic conditions to record $121.8 \mathrm{mg} \mathrm{l}^{-1}$ at $12^{\text {th }}$ day under static glucose medium compared to 69.1 
$\mathrm{mg} \mathrm{l}^{-1}$ at $26^{\text {th }}$ day under aerated medium. It seems that presence of organic carbon source enhanced chlorophyll productivity for this organism in a short period of time. It was obvious that molasses medium inhibited $N$. muscorum growth completely over all the experiment period.

\section{Total lipid content}

An obvious significant variation in lipid content was observed between species under different culture conditions (Table 1). The lipid content of A. laxa showed gradual increase during exponential phase for all the treatments but with different pattern of amount produced.
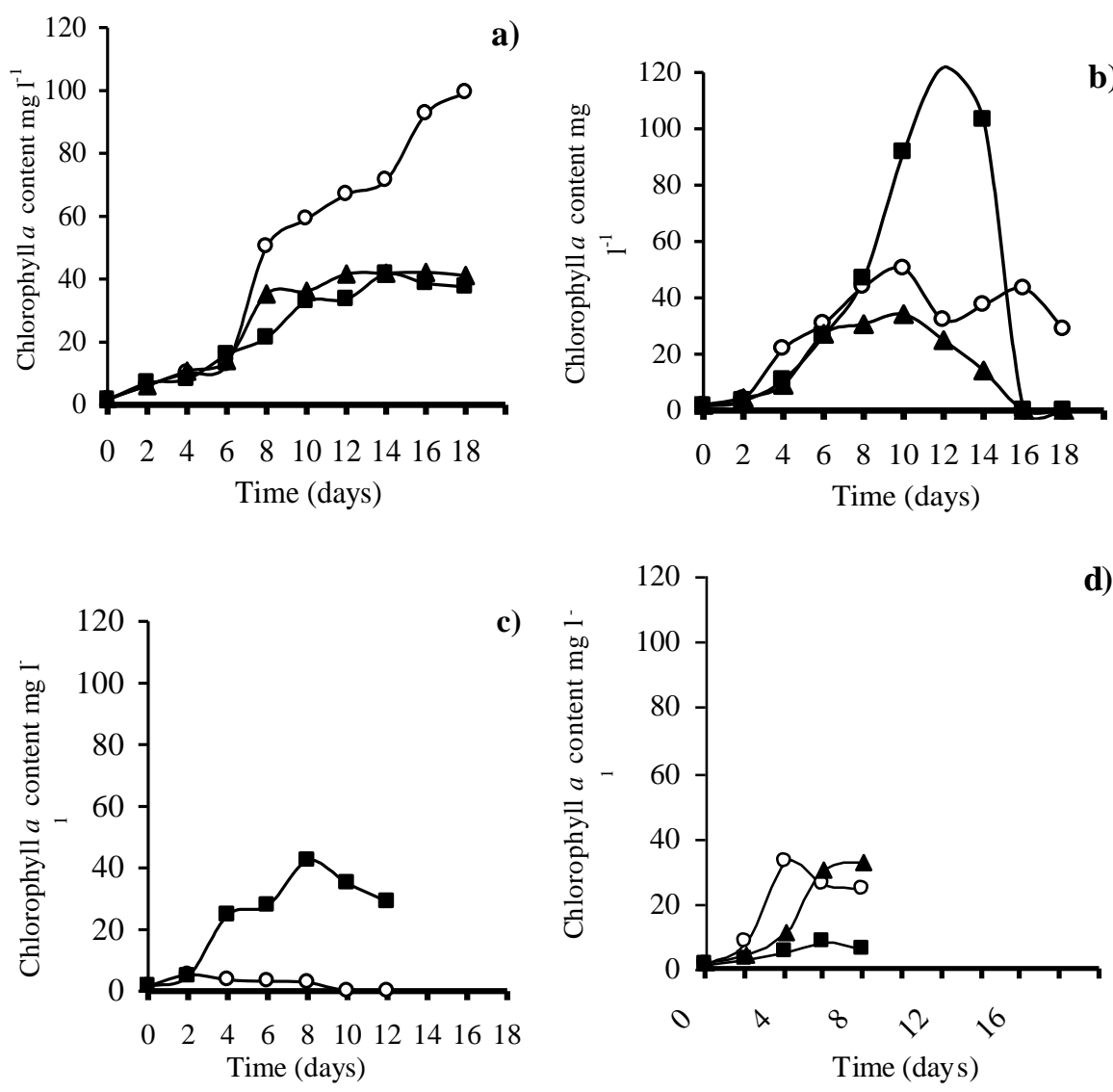

Figure 2. Chlorophyll a content $\mathrm{mg} \mathrm{L}^{-1}$ of Anabaena laxa (O), Anabaena fertilissima (匹) and Nostoc muscorum ( $\triangle$ ) at different growth media conditions a) aerated $(0.3 \%$ $\left.\mathrm{CO}_{2}\right)$, b) static glucose $\left.(1 \%, \mathrm{w} / \mathrm{v}), \mathrm{c}\right)$ molasses $(0.7 \%, \mathrm{v} / \mathrm{v})$ and d) aerated enriched glucose $(1 \%, \mathrm{w} / \mathrm{v})$ medium. Values are the mean of three replicates. 
Glucose enriched medium recorded the highest significant lipid content, about 6.5 folds of zero time extent, compared with the other treatments. Meanwhile, aerated treatment produced about 3.6 folds of zero time after 12 days. A close value was achieved under $0.7 \%(\mathrm{v} / \mathrm{v})$ molasses medium to reach 3.6 folds of starting point but in a shorter time period after only two days of incubation period.

A. fertilissima recorded high lipid content (307.6 $\mu \mathrm{g} \mathrm{g}^{-1}$ fresh wt.) after two days when incubated under aerated enriched glucose medium. This amount was the highest lipid content compared with the other treatments. Molasses treatment exceeded lipid content by about 5 folds of zero time value. The lipid content in aerated medium fluctuated from high to low but still lower than the start point. With respect to incubation periods it seems that aerated enriched glucose medium is the most promised treatment for the rate of lipid synthesis for A. fertilissima, as it showed high significant differences at $2^{\text {nd }}, 4^{\text {th }}, 6^{\text {th }}$ and $8^{\text {th }}$ days compared to the other treatments at the same time intervals.

The highest lipid content for $N$. muscorum was recorded at $10^{\text {th }}$ day under glucose medium which was about 7.2 folds of zero time, and for aerated enriched glucose medium the highest value was obtained at $8^{\text {th }}$ day was $182.5 \mu \mathrm{g} \mathrm{g}^{-1}$ fresh wt. In contrast, $N$. muscorum growth was inhibited completely under $0.7 \%(\mathrm{v} / \mathrm{v})$ molasses medium.

It seems that after reaching the maximum value, the lipid content declined for all the treatments specially glucose and aerated glucose medium where after $8^{\text {th }}$ day the death of the organism clearly appeared in the flasks.

Lipid content percentage of A. laxa, A. fertilissima and N. muscorum when compared with the initial lipid content at different growth media conditions was represented in Fig. 3. Aerated BG11 0 growth medium for both A. laxa and $N$. muscorum enlarged the lipid content production gradually during exponential phase till they reached their maximum values during stationary phase. On the contrary, A. fertilissima showed a marked reduction of lipid production during the incubation period; moreover, enriched glucose medium exhibited the highest rates. $N$. muscorum recorded the maximum yield $(628.4 \%)$ followed by $A$. laxa (552.3\%) and A. fertilissima (220.1\%) after 10, 8 and 4 days, respectively. While for molasses medium A. fertilissima exhibited the highest rate $(342.4 \%)$ at $6^{\text {th }}$ day followed by $A$. laxa $(255.7 \%)$ at $2^{\text {nd }}$ day. Whereas, $N$. muscorum was inhibited completely and couldn't recover again. Aerated enriched glucose medium improved the lipid rate content in case of A. fertilissima $(512.4 \%)$ at $2^{\text {nd }}$ day followed by $N$. muscorum $(424.3 \%)$ at $8^{\text {th }}$ day, while, A. laxa recorded the lowest rate $(225.1 \%)$ at $8^{\text {th }}$ day. 
Fekry M. Ghazal et al.

Table 1. Total lipid content ( $\mu \mathrm{g} \mathrm{g}^{-1}$ fresh wt.) of Anabaena laxa, Anabaena fertilissima and Nostoc muscorum at different growth media conditions a) aerated $\left(0.3 \% \mathrm{CO}_{2}\right)$, b) static glucose $(1 \%, \mathrm{w} / \mathrm{v})$, c) molasses $(0.7 \%, \mathrm{v} / \mathrm{v})$ and $d)$ aerated enriched glucose $(1 \%, \mathrm{w} / \mathrm{v})$ medium.

\begin{tabular}{|c|c|c|c|c|c|}
\hline \multicolumn{6}{|c|}{ Anabaena laxa } \\
\hline $\mathrm{T}_{\text {Time (days) }}^{\text {Media condition }}$ & Aerated & Static glucose & Molasses & $\begin{array}{l}\text { aerated enriched } \\
\text { glucose }\end{array}$ & LSD \\
\hline 0 & $45.0 \pm 0.7$ & $45.0 \pm 0.7$ & $45.0 \pm 0.7$ & $45.0 \pm 0.7$ & 0.6 \\
\hline 2 & $97.9 \pm 8.5$ & $187.3 \pm 20.5$ & $160.3 \pm 5.2$ & $110 . \pm 3.7$ & 8.6 \\
\hline 4 & $102.4 \pm 6.4$ & $247.7 \pm 11.7$ & $158.7 \pm 4.2$ & $148.8 \pm 4.7$ & 6.7 \\
\hline 6 & $111.3 \pm 1.1$ & $237.0 \pm 11.3$ & $133.2 \pm 4.2$ & $150.6 \pm 12.4$ & 6.4 \\
\hline 8 & $110.2 \pm 3.2$ & $293.9 \pm 12.4$ & $101.1 \pm 3.3$ & $146.5 \pm 1.9$ & 4.9 \\
\hline 10 & $130.3 \pm 6.9$ & $181.7 \pm 9.5$ & 0 & 0 & 5.6 \\
\hline 12 & $162.4 \pm 5.1$ & $122.3 \pm 8.2$ & 0 & 0 & 4.4 \\
\hline 14 & $139.4 \pm 5.4$ & 0 & 0 & 0 & 2.0 \\
\hline 16 & $137.4 \pm 3.0$ & 0 & 0 & 0 & 2.4 \\
\hline 18 & $136.2 \pm 1.9$ & 0 & 0 & 0 & 2.6 \\
\hline LSD & 4.0 & 8.2 & 2.2 & 3.6 & \\
\hline \multicolumn{6}{|c|}{ Anabaena fertilissima } \\
\hline 0 & $50.2 \pm 2.8$ & $50.2 \pm 2.8$ & $50.2 \pm 2.8$ & $50.2 \pm 2.8$ & 2.3 \\
\hline 2 & $41.2 \pm 1.9$ & $74.4 \pm 1.5$ & $127.5 \pm 8.3$ & $307.6 \pm 17.3$ & 7.1 \\
\hline 4 & $38.4 \pm 2.3$ & $160.8 \pm 3$ & $156.9 \pm 9.9$ & $303.8 \pm 22.5$ & 9.1 \\
\hline 6 & $30 \pm 1.4$ & $156.03 \pm 3$ & $222.2 \pm 9.8$ & $258.6 \pm 14.8$ & 7.0 \\
\hline 8 & $32.3 \pm 3.1$ & $108.7 \pm 1.5$ & $185.2 \pm 21.4$ & $207.7 \pm 18.4$ & 10.4 \\
\hline 10 & $20.7 \pm 2.2$ & 0 & $292.5 \pm 19.4$ & 0 & 7.2 \\
\hline 12 & $27.7 \pm 3.9$ & 0 & $138.9 \pm 9.5$ & 0 & 3.9 \\
\hline 14 & $45 \pm 1.2$ & 0 & 0 & 0 & 1.3 \\
\hline 16 & $36.2 \pm 3.2$ & 0 & 0 & 0 & 1.6 \\
\hline 18 & $45.1 \pm 0.1$ & 0 & 0 & 0 & 1.0 \\
\hline LSD & 2.0 & 1.4 & 8.9 & 9.6 & \\
\hline \multicolumn{6}{|c|}{ Nostoc muscorum } \\
\hline 0 & $34.8 \pm 0.1$ & $34.8 \pm 1$ & $34.8 \pm 0.1$ & $34.8 \pm 0.1$ & 0.8 \\
\hline 2 & $38.5 \pm 0.5$ & $22.9 \pm 2.8$ & 0 & $119.8 \pm 2.8$ & 1.7 \\
\hline 4 & $71.5 \pm 0.99$ & $53.8 \pm 1.6$ & 0 & $170.3 \pm 5.2$ & 2.1 \\
\hline 6 & $72.2 \pm 9.2$ & $81.9 \pm 3.4$ & 0 & $168.1 \pm 21.2$ & 8.6 \\
\hline 8 & $72.1 \pm 3.1$ & $130.6 \pm 4.0$ & 0 & $182.46 \pm 4.7$ & 3.7 \\
\hline 10 & 77. $8 \pm 7.0$ & $253.5 \pm 16.9$ & 0 & 0 & 6.8 \\
\hline 12 & $66.2 \pm 7.5$ & $220.9 \pm 12.9$ & 0 & 0 & 5.7 \\
\hline 14 & $73.3 \pm 0.9$ & 0 & 0 & 0 & 0.8 \\
\hline 16 & $85.6 \pm 9.5$ & 0 & 0 & 0 & 4.3 \\
\hline 18 & $43.1 \pm 1.9$ & 0 & 0 & 0 & 0.7 \\
\hline LSD & 4.4 & 5.8 & 0.2 & 5.8 & \\
\hline
\end{tabular}

Where: LSD, least significance difference; Data are expressed as mean $\pm \operatorname{SD}(n=3)$.

Egyptian J. of Phycol. Vol. 13, 2012 

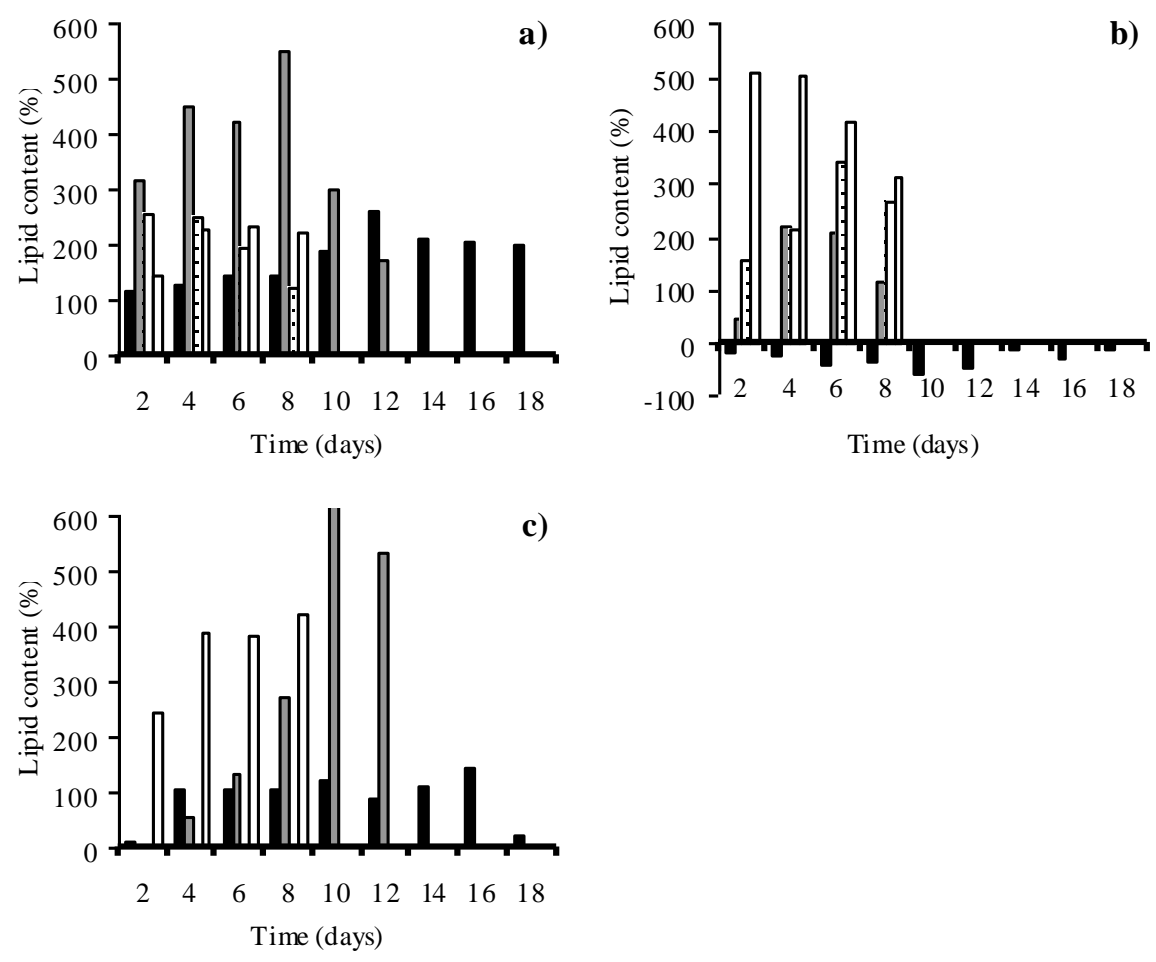

Figure 3. Lipid content percentage of a) Anabaena laxa, b) Anabaena fertilissima and c) Nostoc muscorum when compared with the initial lipid content at different growth media conditions; aerated $\left(0.3 \% \mathrm{CO}_{2}\right)(\square)$, static glucose $(1 \%$, w/v) $(\square)$, molasses $(0.7 \%, v / v)($ 国 $)$ and aerated enriched glucose $(1 \%, w / v)$ medium $(\square)$. Values are the mean of three replicates.

Table 2 shows, analyses of all selected species have the same types of fatty acids but with considerable differences in quantities. Generally saturated fatty acids is the most abundant of total fatty acids composition compared with both mono and poly-unsaturated fatty acids for the three cyanbacterial spp. A. fertilissima exhibited. the highest values for saturated fatty acids $(83.3 \%)$ followed by $N$. muscorum (80\%) then A. laxa (71.2\%). Accordingly, A. laxa has the highest values for both mono and polyunsaturated fatty acids composition among the investigated spp. (23.3 and $5.6 \%$, respectively) followed by $N$. muscorum and A. fertilissima. With regard to A. laxa, stearic acid was the most abundant saturated fatty acid $(25.2 \%)$, palmitoleic acid was the dominant mono-unsaturated fatty acid $(13.2 \%)$, and arachidonic represented the most abundant poly-unsaturated fatty acids acid (3.4\%). Myristic acid was detected in high levels for N. muscorum 
followed by A. fertilissima, also, palmitoleic acid recorded the highest percentage of mono-unsaturated fatty acids for both $N$. muscorum and A. fertilissima.

Table 2. Fatty acids composition in dry weight (\%) of Anabaena laxa, Anabaena fertilissima and Nostoc muscorum grown under static glucose medium (1\%, w/v) during the stationary phase.

\begin{tabular}{|c|c|c|c|c|c|}
\hline \multicolumn{2}{|c|}{ Fatty acid } & Common name & A. laxa & A. fertilissima & N. muscorum \\
\hline \multirow{5}{*}{ 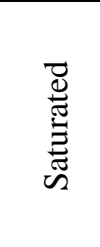 } & C12:0 & Lauric acid & 4.6 & 11.18 & 20.35 \\
\hline & $\mathrm{C} 14: 0$ & Myristic acid & 17.97 & 37.5 & 20.69 \\
\hline & C16:0 & Palmitic acid & 17.6 & 13.8 & 15.04 \\
\hline & C18:0 & Stearic acid & 25.2 & 17.6 & 19.78 \\
\hline & C20:0 & Arachidic acid & 5.8 & 3.25 & 4.13 \\
\hline \multicolumn{3}{|c|}{ Total saturated acids } & 71.17 & 83.3 & 79.99 \\
\hline \multirow{2}{*}{ 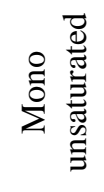 } & $\mathrm{C} 16: 1$ & Palmitoleic acid & 13.2 & 8.6 & 10.17 \\
\hline & C18:1 & Oleic acid & 10.1 & 5.27 & 6.64 \\
\hline \multicolumn{3}{|l|}{ Total } & 23.3 & 13.87 & 16.81 \\
\hline \multirow{3}{*}{ 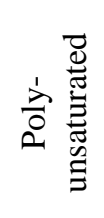 } & $\mathrm{C} 18: 2$ & Linoleic acid & 1.01 & 0.77 & 0.44 \\
\hline & $\mathrm{C} 18: 3$ & Lenolenic acid & 1.2 & 0.43 & 0.29 \\
\hline & $\mathrm{C} 20: 4$ & Arachidonic acid & 3.4 & 1.67 & 2.47 \\
\hline \multicolumn{3}{|l|}{ Total } & 5.61 & 2.87 & 3.2 \\
\hline \multicolumn{3}{|c|}{ Total unsaturated acids } & 28.91 & 16.74 & 20.01 \\
\hline
\end{tabular}

\section{Discussion}

The present study revealed that the maximum growth rate and the highest dry weight were achieved under $1 \%(\mathrm{w} / \mathrm{v})$ glucose static medium. In this context Yamane et al. (2001) reported that about 15-19\% higher growth was obtained in the mixotrophic culture. Furthermore, Guoce et al. (2011) reported that glucose improved the cell growth evidently, the maximal specific growth rate under mixotrophic condition $\left(0.38 \mathrm{~d}^{-1}\right)$ being 1.6-fold of that of photoautotrophic growth. Moreover, fructose was taken up and utilized in Anabaena variabilis for mixotrophic growth (Haury and Spiller 1981; Valiente et al., 1992) and was able to enhance the development and growth of Anabaena azollae in mixotrophic culture. Rozen et al. (1986) and Rozen et al. (1988) demonstrated the potential of mixotrophy growth condition. Guoce et al. (2011) reported that Anabaena sp. 
PCC7120 did not grow on glucose in darkness. Our experiment implied that the utilization of glucose requires the participation of light, and the weak light due to the shading effect at high cell density may also impede mixotrophic growth.

The present investigation indicated that aerated enriched glucose medium exhibited a promised result of dry weight for both A. laxa and A. fertilissima due to presence of glucose besides bubbling air. Similar observation was obtained by Liang et al. (2009) who reported that bubbling air into Chlorella vulgaris culture exerted a positive effect on cell growth. N.muscorum exhibited no growth on $0.7 \%(\mathrm{v} / \mathrm{v})$ molasses medium due to the highly osmotic pressure caused by sugars present in it. This finding is in accordance with Liang et al. (2009), who mentioned that both glucose and glycerol had inhibitory effects at high concentrations. C. protothecoides could not directly use molasses as organic carbon source because raw waste molasses contains $36.24 \%$ of sucrose; in addition, raw waste molasses contains colloidal and other impurities which might inhibit algal cell growth (Yan et al., 2011; Lee et al., 1999). Moreover inhibitory effect of molasses at reducing sugar concentrations above or below the range negatively influenced algal growth. Which might be due to higher osmotic pressure in media caused by higher reducing sugar concentration of molasses. (Yan et al., 2011).

With respect to chlorophyll content it was clearly observed that enriched glucose medium caused a reduction of chlorophyll content for A. laxa and $N$. muscorum than aerated medium. This was attributed to the glucose feeding resulted in massive intracellular accumulation of carbohydrates (glucose, fructose, sucrose and starch) and a delayed but pronounced reduction of the chlorophyll content. Thus, the presence of D-glucose caused a reduction of pigment content in the cell, due to the inhibition of chlorophyll $a$ and phycocyanobilin biosynthesis at the stage of the transformation of their universal precursor. The assumption was made that D-glucose activates a certain macromolecular intracellular regulator, which, in turn, represses the activity of some of the key chloroplast genes (Zvereva et al., 1980).

In contrast A. fertilissima exhibited the highest chlorophyll (a) content under mixotrophic condition ( $1 \%$ glucose, w/v) was $121.4 \mathrm{mg} \mathrm{l}^{-1}$ after 12 days as compared to $33.4 \mathrm{mg} \mathrm{l}^{-1}$ under autotrophic aerated medium at the same day. High cellular density of the culture produced shade which reduced the irradiance into the culture, increasing the chlorophyll content per cell (Saoudi-Helis et al., 1994), this observation agreed with Borsari et al. (2007). It seemed that biosynthesis of chlorophyll in the cyanobacterial cells as a response of addition of carbon sources, D-glucose or molasses to the growth medium had variable effect. It may cause a pronounced increase in total chlorophyll content as in case of A. fertilissima or cause an obvious inhibition as in case of A. laxa and N. muscorum, these actions were strongly related to the genetic criteria of each isolates.

The highest lipid content of A. laxa and N. muscorum were 293.9 and $253.5 \mu \mathrm{g}$ $\mathrm{g}^{-1}$ fresh wt., respectively, that were achieved by the addition of $1 \%(\mathrm{w} / \mathrm{v})$ glucose 
to the culture media. Matsuka et al. (1969) reported that glucose is mainly incorporated into lipids (particularly fatty acids) to optimize growth and production of desired chemicals from microalgae, it is essential to supply the accurate carbon source. Enriched glucose medium gave the highest lipid content rather the other media; so, it clarified why carbon sources assimilated through different metabolic pathways influenced the biochemical composition of microalgae. Liang et al. (2009) reported that maximum lipid productivity (54 $\mathrm{mg}$ $\left.1^{-1} \mathrm{day}^{-1}\right)$ was obtained when cells were grown with glucose $(1 \%$ w/v) within 6 days. However the highest lipid content of A. fertilissima (292.5 $\mu \mathrm{g} \mathrm{g}^{-1}$ fresh wt.) was achieved by utilizing molasses medium $(0.7 \%, \mathrm{v} / \mathrm{v})$. This was due to the fact that sugarcane molasses is rich in nutrients. Besides the great concentration of carbohydrates, it had nitrogenous substances, vitamins, trace elements and many other kinds of ingredients that consist mainly of $48 \%$ sugars. Its composition varies depending on the sugarcane used for the production of sugar (Crueger and Crueger, 1989). This finding was in accordance with Yan et al. (2011), who reported that increasing molasses the content lipid increased. Waste molasses was confirmed as a sole source of full nutrients to totally replace glucose-based medium in support of rapid growth and high oil yield from algae (Yan et al., 2011). This investigation recorded that, saturated fatty acids were the most abundant of total fatty acids composition compared with both mono and poly unsaturated fatty acids for our examined cyanbacterial spp. under $1 \%(\mathrm{w} / \mathrm{v})$ static glucose medium. In accordance with Chu $\boldsymbol{e t}$ al. (1995), the relative amounts of $\mathrm{C} 16: 0, \mathrm{C} 18: 0, \mathrm{C} 18: 1$ and $\mathrm{C} 18: 2$ increased at the expense of $\mathrm{C} 18: 3$ in the carbon supplemented culture and at glucose concentrations higher than $0.1 \%(\mathrm{w} / \mathrm{v})$. Generally, microalgal triglycerides contain saturated and monosaturated fatty acids with $\mathrm{C}_{16}$ and $\mathrm{C}_{\mathrm{I} 8}$ profile (Bertoldi et al., 2006; Hu et al., 2008; Meng et al., 2009). Microalgae with higher levels of triacylglycerol should contain higher proportions of saturated and mono-unsaturated fatty acids and lower proportion of poly-unsaturated fatty acid (Dunstan et al., 1993).

A. laxa, A. fertilissima and N.muscorum recorded high percentage of palmitoleic fatty acid (C16:1). This finding is in accordance with Sallal $\boldsymbol{e t}$ al. (1990) who reported that, in lipids of $A$. cylindrical, palmitic, linoleic and linolenic acids were predominant. $N$. canina lipids contained palmitic, palmitoleic, oleic and linoleic acids as major acyl moieties, whereas in $N$. muscorum palmitic, palmitoleic, hexadecadienoic, oleic and linoleic acids were predominant. With regard to polyunsaturated fatty acids, arachidonic acid exhibited the greatest value for the treated cyanobacterial spp.

\section{Conclusion}

This work reported the first results of a large study of the biological removal of $\mathrm{CO}_{2}$ from flue gases using microalgae and using glucose sugar as organic carbon source. 


\section{References}

Allen, M.M. and Stanier, R.Y. (1968). Selective isolation of blue-green algae from water and soil. Journal of General Microbiology, 51: 203-209.

Arnon, D.I. (1949). Copper enzymes in isolated chloroplasts. Polyphenoloxidase in Beta vulgaris. Plant Physiology, 24: 1-15.

Barnes, H. and Blackstock, J. (1973). Estimation of lipids in marine animals and tissues: Detailed investigation of the sulphophosphovanilun method for total lipids. Journal of Experimental Marine Biology and Ecology, 12: 103118.

Bertoldi, F.C.; Sant'Anna, E.; Da Costa Braga, M.V. and Oliveira, J.L.B. (2006). Lipids, fatty acids composition and carotenoids of Chlorella vulgaris cultivated in hydroponic wastewater. Grasas Aceites, 57: 270-274.

Borsari, R.R.J.; Morioka, L.R.I.; Ribeiro M.L.L.; Buzato J.B. and Pinotti M.H.P. (2007). Mixotrophic growth of Nostoc sp. on glucose, sucrose and sugarcane molasses for phycobiliprotein production. Maringá, 29: 9-13.

Chu, W.L.; Siew-Moi, P. and Swee-Hock, G. (1995). Influence of carbon source on growth, biochemical composition of Ankistrodesmus convlutus. Journal of Applied Phycology, 7: 59-64.

Crueger, W. and Crueger, A. (1989). Biotecnología: Manual de Microbiologia Industrial. Acribia SA, Zaragoza

de Swaaf, M.E.; Pronk, J.T. and Sijtsma, L. (2003a). Fed-batch cultivation of the docosahexaenoic-acid-producing marine alga Crypthecodinium cohnii on ethanol. Applied Microbiology and Biotechnology, 61: 40-43.

de Swaaf, M.E., Sijtsma, L. and Pronk, J.T. (2003b). High-cell density fedbatch cultivation of the docosahexaenoic acid producing marine alga Crypthecodinium cohnii. Biotechnology and Bioengineering, 81: 666-672.

Dunstan, G.A.; Volkman, J.K.; Barrett, S.M. and Garland, C.D. (1993). Changes in the lipid composition and maximization of the polyunsaturated fatty acid content of three microalgae grown in mass culture. Journal of Applied Phycology, 5: 71-83.

Guoce, Y.; Dingji, S.; Zhaoling, C.; Wei, C. and Fan, O. (2011). Growth and physiological features of cyanobacterium Anabaena sp. strain PCC 7120 in a glucose-mixotrophic culture. Chinese Journal of Chemical Engineering, 19: 108-115.

Harwood, J.L. and Caterson, B. (2006). Dietary omega-3 polyunsaturated fatty acids and inflammation. Lipid Technology, 18: 7-10.

Haury, J.F. and Spiller, H. (1981). Fructose uptake and influence on growth of and nitrogen fixation by Anabaena variabilis. Journal of Bacteriology, 147: 227-235.

Hu, Q.; Sommerfeld, M.; Jarvis, E.; Ghirardi, M.; Posewitz, M.; Seibert, M. and Darzins, A. (2008). Microalgal triacyglycerols as feedstocks for biofuel production: perspective and advances. Plant Journal, 54: 621-639. 
Lee, P.C.; Lee, W.G.; Lee, S.Y. and Chang, H.N. (1999). Effects of medium components on the growth of Anaerobiospirillum succiniciproducens and succinic acid production. Process Biochemistry, 35: 49-55.

Leganés, F.; Sánchez-Maeso, E. and Fernández-Valiente, E. (1987). Effect of indolacetic acid on growth and dinitrogen fixation in cyanobacteria. Plant Cell Physiology, 28: 529-533.

Liang, Y.; Nicolas, S. and Cui, Y. (2009). Biomass and lipid productivities of Chlorella vulgaris under autotrophic, heterotrophic and mixotrophic growth conditions. Biotechnology Letters, 31: 1043-1049.

Matsuka, M.; Miyachi, S. and Hase, E. (1969). Further studies on the metabolism of glucose in the process of glucose -bleaching of Chlorella protothecoides. Plant Cell Physiology, 10: 513-526.

Meng, X.; Yang, J.; Xu, X.; Zhang, L.; Nie, Q. and Xian, M. (2009). Biodiesel production from oleaginous microorganisms. Renewable Energy, 34: 1-5.

Miao, X.L. and Wu, Q.Y. (2006). Biodiesel production from heterotrophic microalgal oil. Bioresource Technology, 97: 841-846.

Naik, S.N.; Meher, L.C. and Sagar, D.V. (2006). Technical aspects of biodiesel production by transesterification - a review. Renewable and Sustainable Energy Reviews, 10: 248-268.

Raja, R.; Hemaiswarya, S.; Kumar, N.A.; Sridhas, S. and Rengasamy, R. (2008). A perspective on the biotechnological potential of microalgae. Critical Reviews in Microbiology, 34: 77-88.

Renaud, S.M.; Thinh, L.V. and Parry, D.L. (1999). The gross chemical composition and fatty acid composition of 18 species of tropical Australian microalgae for possible use in mariculture. Aquaculture, 170: 147-159.

Rittmann, B.E. (2008). Opportunities for renewable bioenergy using microorganisms. Biotechnology and Bioengineering, 100: 203-212.

Ronald, S.K. and Ronald, S. (1991). Person's composition and analysis of foods. $9^{\text {th }}$ Ed. Longman Scientific and Technical USA pp. 629-634

Rozen, A.; Arad, H.; Schönfeld, M. and Tel-Or, E. (1986). Fructose supports glycogen accumulation, heterocysts differentiation, $\mathrm{N}_{2}$ fixation and growth of the isolated cyanobiont Anabaena azollae. Archives of Microbiology, 145: 187-190.

Rozen, A.; Arad, H.; Schönfeld, M. and Tel-Or, E. (1988). Fructose-enhanced development and growth of the $\mathrm{N}_{2}$-fixing cyanobiont Anabaena azollae. Zeitschrift fuer Naturforschung, 43c: 408-412.

Sallal, A.K.; Nimer, N.A. and Radwan, S.S. (1990). Lipid and fatty acid composition of freshwater cyanobacteria. Journal of General Microbiology 136: 2043-2048.

Saoudi-Helis, L.; Dubacq, J-P.; Marty, Y.; Samain, J-F. and Gudin, C. (1994). Influence of growth rate on pigment and lipid composition of the microalga Isochrysis aff. galbana clone T.iso. Journal of Applied Phycology, 6: 315-322. 
Valiente, E.F.; Nieva, M.; Avendano, M.C. and Maeso, E.S. (1992). Uptake and utilization of fructose by Anabaena variabilis ATCC 29413. Effect on respiration and photosynthesis. Plant and Cell Physiology, 33: 307-313.

Wu, Q.Y.; Yin, S.; Sheng, G.Y. and Fu, J.M. (1992). A comparative study of gases generated from stimulant thermal degradation of autotrophic and heterotrophic Chlorella. Prog. Nat. Sci., 3:435-440

Xu, H.; Miao, X. and Wu, Q. (2006). High quality biodiesel production from a microalga Chlorella protothecoides by heterotrophic growth in fermenters. Journal of Biotechnology, 126: 499-507.

Xu, Z.B.; Yan, X.J.; Pei, L.Q.; Luo, Q.J. and Xu, J.L. (2008). Changes in fatty acids and sterols during batch growth of Pavlova viridis in photobioreactor. Journal of Applied Phycology, 20: 237-243.

Yamane, Y-i.; Utsunomiya, T.; Watanabe, M. and Sasaki, K. (2001). Biomass production in mixotrophic culture of Euglena gracilis under acidic condition and its growth energetics. Biotechnology Letters, 23: 1223-1228.

Yan, D.; Lu, Y.; Chen, Y.F. and Wu, Q. (2011). Waste molasses alone displaces glucose-based medium for microalgal fermentation towards cost-saving biodiesel production. Bioresource Technology, 102: 6487-6493.

Zvereva, M.G.; Klimova, M.A. and Semenenko, V.E. (1980). Repression of RNA synthesis and disturbances in the activity of photochemical systems of the chloroplast as affected by 2-deoxy-D -glucose and accumulation of assimilates in Chlorella cells. Russian Journal of Plant Physiology, 27: 1218-1228. 


\title{
الأنتاجية و المحتوى الدهنى وتركيب الحمض الدهني لبعض السلالات المختارة من

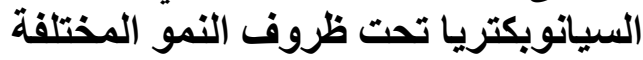

\author{
فكرى غزال 1 ، علا حمودة ${ }^{2}$ ، محمد عبد الحميد 2 ، شريف حسن 2 ، سهام حامد 1 \\ 1- معهد بحوث الأراضى والمياه والبيئة ـ ـ مركز البحوث الزراعية ـ الجبزة- مصر

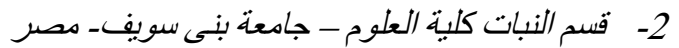

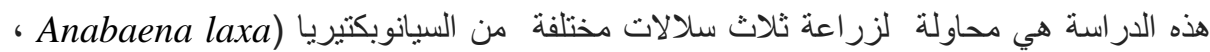

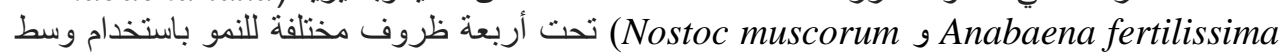

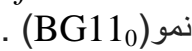

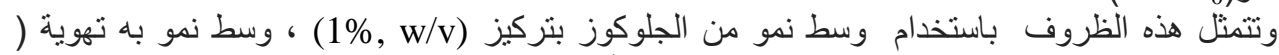

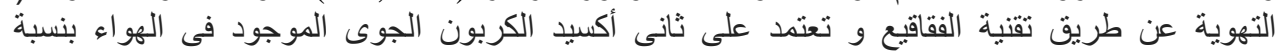

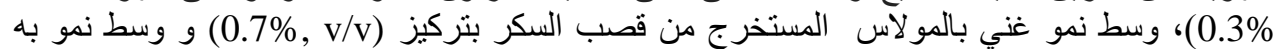

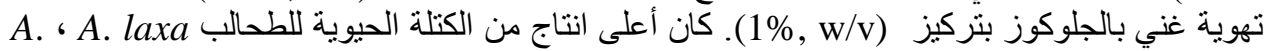
N. muscorum و fertilissima

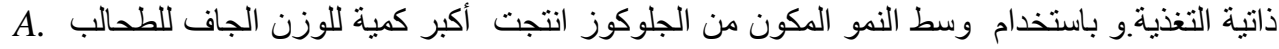

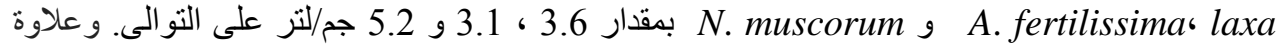

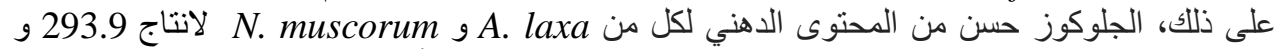

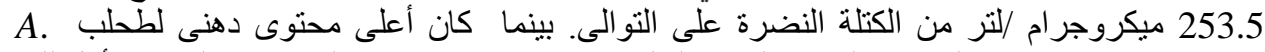

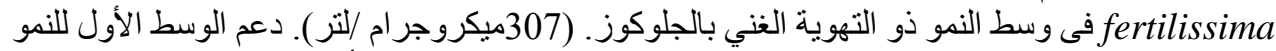

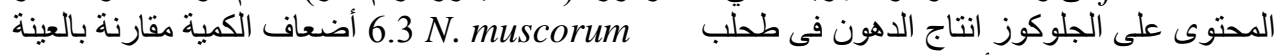

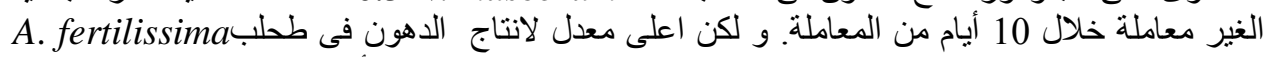

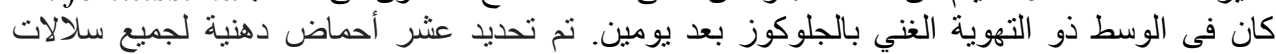

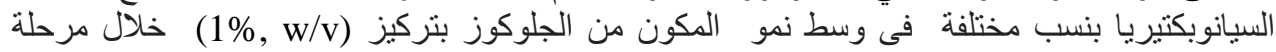

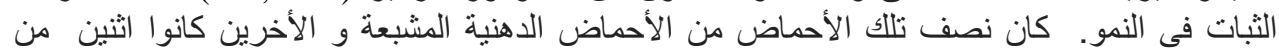

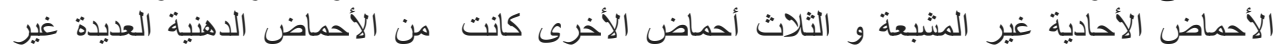

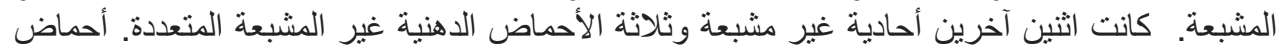
الميريستيك، البالمتيوليك و الأر اكيدونيك كانت الأكثر وفرة بين جميع العز لات التين المختبرة. 